\title{
Seaweed Oligosaccharides Stimulate Plant Growth by Enhancing Carbon and Nitrogen Assimilation, Basal Metabolism, and Cell Division
}

\author{
Alberto González • Jorge Castro • Jeannette Vera • \\ Alejandra Moenne
}

Received: 16 July 2012/Accepted: 25 September 2012/Published online: 11 December 2012

(C) The Author(s) 2012. This article is published with open access at Springerlink.com

\begin{abstract}
It is now well established that plant cell wall oligosaccharides can stimulate or inhibit growth and development in plants. In addition, it has been determined that seaweed (marine algae) cell wall polysaccharides and derived oligosaccharides can enhance growth in plants. In particular, oligo-alginates obtained by depolymerization of alginates from brown seaweeds increase growth of different plants by enhancing nitrogen assimilation and basal metabolism. Interestingly, oligo-alginates also stimulate growth of marine and fresh water green microalgae, increasing the content of fatty acids. On the other hand, oligo-carrageenans obtained by depolymerization of carrageenans from red seaweeds increase growth of tobacco plants by enhancing photosynthesis, nitrogen assimilation, basal metabolism, and cell division. In addition, oligocarrageenans increase protection against viral, fungal, and bacterial infections in tobacco plants, which is determined, at least in part, by the accumulation of several phenylpropanoid compounds (PPCs) with antimicrobial activity. Moreover, oligo-carrageenans stimulate growth of 3-yearold Eucalyptus globulus trees by increasing photosynthesis, nitrogen assimilation, and basal metabolism. Furthermore, oligo-carrageenans induce an increase in cellulose content and in the level of essential oil and some PPCs with antimicrobial activities, suggesting that defense against pathogens may be also enhanced. Thus, seaweed oligosaccharides induce a dual beneficial effect in plants and trees, enhancing growth, which is determined by the increase in carbon and nitrogen assimilation, basal
\end{abstract}

A. González · J. Castro $\cdot$ J. Vera $\cdot$ A. Moenne $(\square)$

Laboratory of Marine Biotechnology, Faculty of Chemistry

and Biology, University of Santiago, Casilla 40, Correo 33,

Santiago, Chile

e-mail: alejandra.moenne@usach.cl metabolism, and cell division, and defense against pathogens, which is determined by the accumulation of compounds with antimicrobial activities. In this sense, molecular mechanisms that potentially interconnect activation of plant growth and defense responses are discussed.

Keywords Seaweed oligosaccharides - Oligo-alginates · Oligo-carrageenans · Microalgae $\cdot$ Plants · Trees

\section{Introduction}

It is now clearly established that plant oligosaccharides can activate or inhibit plant growth and development (Albersheim and others 1992; John and others 1997). This oligosaccharide-dependent regulatory phenomenon was initially described in pea treated with an oligo-xyloglucan (OX) with a degree of polymerization (DP) of 7, obtained by acid depolymerization of xyloglucans from plant cell walls that inhibit auxin-induced growth in pea stems (York and others 1984; Augur and others 1992). In addition, oligogalacturonides (OGs) with a DP of 25-50, obtained by depolymerization of pectin from plant cell walls, modulate tobacco explant morphogenesis leading to a differential formation of flowers, floral shoots, vegetative buds, and roots, depending on the concentration of OGs and the $\mathrm{pH}$ of the culture medium (Tran Than Van and others 1985; Eberhard and others 1989). Moreover, it was determined that an OX with a DP of 9 stimulates elongation of etiolated pea stems in the absence of auxins (McDougall and Fry 1990). Furthermore, synthetic lipo-chitooligosaccharides (LCOs), which correspond to nodulation factors secreted by rhizobial bacteria, are constituted by four $\mathrm{N}$-acetyl-glucosamine units linked to a molecule of cis-11octadecanoic acid, stimulate formation of calli from 
tobacco protoplasts (Röhrig and others 1995, 1996). In addition to the effect on regulation of plant growth and development, it was determined that plant OGs and fungal $\beta$-glucans elicit defense responses in plants that lead to the accumulation of phytoalexins, which are compounds with antimicrobial activities, such as terpenes, terpenoids, alkaloids, and phenylpropanoid compounds (PPCs), which in turn leads to an enhanced protection against pathogens (Nothangel and others 1983; Jin and West 1984; Sharp and others 1984). On the other hand, it was initially demonstrated that seaweed oligo-carrageenans kappa, lambda, and iota, with DPs of $1-3,3-9$, and 2-6, respectively, obtained by enzyme depolymerization of red seaweed carrageenans, stimulate embryogenesis of broccoli microspores, mainly oligo-carrageenan lambda (Lemonnier-Le Penhuizic and others 2001).

\section{Oligo-alginates Stimulate Growth in Plants}

Alginates are the major components of brown seaweed cell walls and they are made up of poly(D-glucuronic acid) blocks (PG), poly(D-mannuronic acid) blocks (PM), and alternating blocks of D-glucuronic and D-mannuronic residues (GM) (for models see Vera and others 2011). Oligo-alginates have been obtained by digestion of alginates or PM and PG fractions with an alginate lyase, by treatment with $\gamma$-radiation, or by acid hydrolysis. In particular, it has been shown that alginates, depolymerized using $\gamma$-radiation, at concentrations of $0.5-1 \mathrm{mg} \mathrm{ml}^{-1}$, enhance growth of rice and peanut plants cultivated hydroponically (Hien and others 2000). In addition, a mixture of oligo-alginates with a DP of 2-8 (mainly oligoalginates constituted by $3-5$ residues), obtained by degradation of alginates with a bacterial alginate lyase, at a concentration of $0.5-3 \mathrm{mg} \mathrm{ml}^{-1}$, stimulated growth of roots in lettuce (Iwasaki and Matsubara 2000). Moreover, a mixture of PM and PG oligosaccharides with a DP of 3-9, obtained by digestion of the PM and PG fractions with a bacterial alginate lyase, at a concentration of $0.75-1.5 \mathrm{mg} \mathrm{ml}^{-1}$, stimulated elongation of carrot and rice roots but independent fractions did not exhibit the growthpromoting effect (Xu and others 2003). Furthermore, PM and PG oligosaccharides, obtained by digestion of PM and PG fractions with a marine bacteria alginate lyase having a DP of 3, induce germination of maize seeds with a maximal activity at a concentration of $0.75 \mathrm{mg} \mathrm{ml}^{-1}$ (Hu and others 2004). In addition, the oligo-alginate PM (or Poly$\mathrm{Ma}$ ), obtained by acid hydrolysis of PM fraction, at a concentration of $0.5 \mathrm{mg} \mathrm{ml}^{-1}$, increased height and foliar biomass in tobacco plants, but the oligo-alginate PG (or Poly-Gu), obtained by acid hydrolysis of the PG fraction, did not induce this effect (Laporte and others 2007).
Interestingly, the oligo-alginate fraction Poly-Ma increased protection against tobacco mosaic virus (TMV) infection in tobacco plants. Thus, oligo-alginate Poly-Ma has a dual beneficial effect of enhancing growth and defense against pathogens in tobacco plants, suggesting that signaling pathways involved in plant growth and defense may be interconnected.

More recently, a mixture of oligo-alginates, obtained by degradation of alginates with $\gamma$-radiation, at a concentration ranging from 0.02 to $0.1 \mathrm{mg} \mathrm{ml}^{-1}$, increased shoot and root length, shoot dry weight, content of total chlorophylls and carotenoids, nitrate reductase activity involved in nitrogen assimilation, and alkaloid contents, mainly morphine and codeine, in opium poppy (Papaver somniferum) plants (Khan and others 2011). Furthermore, alginates degraded with $\gamma$-radiation, at a concentration from 0.02 to $0.1 \mathrm{mg} \mathrm{ml}^{-1}$, increased shoot and root length of fennel plants (Foeniculum vulgare), the weight of fennel tubers, seed yield, content of total chlorophylls, carotenoids, and proline, nitrate reductase activity, and the level of essential oil (Sarfaraz and others 2011).

\section{Oligo-alginates Stimulate Growth in Microalgae}

A mixture of oligo-alginates, obtained by degradation of alginate with a bacterial alginate lyase, stimulates growth of the marine green microalga Nannochloropsis oculata, which is used to feed bivalave and fish species (Yokose and others 2009). In particular, the optimal growth was obtained using the oligo-alginate mixture at a concentration of $20 \mathrm{mg} \mathrm{ml}^{-1}$ and the growth-promoting activity slightly decreased at $40 \mathrm{mg} \mathrm{ml}^{-1}$. It is interesting to note that the concentration of the oligo-alginate mixture required to promote growth in $N$. oculata was around 20 times higher than that used to stimulate growth in plants (see above). In addition, the latter oligo-alginate mixture also stimulates growth of the diatom Chaetoceros gracilis but did not enhance that of the diatom Skeletonema sp. or that of the marine bacteria Edwardsiella tarda, indicating a speciespecific growth-promoting effect of the oligo-alginate mixture in microalgae (Yokose and others 2010). Furthermore, a mixture of alginate oligosaccharides, obtained by degradation of alginates using an alginate lyase, at a concentration of $1 \mathrm{mg} \mathrm{ml}^{-1}$, stimulates growth of the freshwater green microalga Chlamydomonas reinhardtii, whereas a mixture of oligo-alginates, obtained by acid hydrolysis of alginates, did not exhibit growth-promoting activity (Yamasaki and others 2012). Interestingly, the content of some fatty acids increased in C. reinhardtii treated with enzyme-degraded oligo-alginates, mainly, C16:0, C18:2, and C18:3 fatty acids, but the level of C18:0 slightly decreased and the mixture of oligo-alginates 
obtained by acid hydrolysis failed to increase fatty acid content (Yamasaki and others 2012). Thus, the oligo-alginate mixture not only has a growth-promoting effect but also increases the content of fatty acids in a green microalga, which could be very useful for biodiesel production in the future.

\section{Carrageenans and Oligo-carrageenans Stimulate Growth in Plants}

Carrageenans are the major components of red seaweed cell walls and they are composed of sulfated galactose and, in some cases, anhydrogalactose residues. In particular, carrageenan kappa has one sulfate group per disaccharide unit and anhydrogalactose residue, carrageenan lambda has three sulfate groups per disaccharide unit, and carrageenan iota has two sulfate groups per disaccharide unit and anhydrogalactose residue (for models see Vera and others 2011). Thus, the degree of sulfation increases in carrageenans kappa, iota, and lambda, and only carrageenans kappa and iota have anhydrogalactose residue. It was initially shown (Mercier and others 2001) that the nondepolymerized carrageenans kappa and lambda increased defense responses in tobacco plants, but protection against a microbial infection was not examined in that work. In addition, nondepolymerized lambda carrageenan slightly decreased the level of transcripts encoding the small subunit of ribulose 1,5-bisphosphate carboxylase/oxygenase (rubisco) enzyme, which suggests that plant growth may be inhibited (Mercier and others 2001). In contrast, it was further shown that the nondepolymerized carrageenan kappa, applied to the soil at a concentration of $1 \mathrm{mg} \mathrm{g}^{-1}$ or used as a water solution sprayed on leaves, at a concentration of 0.1 microequivalents of glucose $\mathrm{ml}^{-1}$, stimulated growth, increasing height, number of pods, and leaves, and induced an early flowering in chickpea (Cicer arietinum) plants (Bi and others 2011). However, these results contrast with those obtained by our group which indicated that oligo-carrageenan kappa was much more effective than nondepolymerized carrageenan kappa in enhancing growth of tobacco plants, and that oligo-carrageenan iota induced protection against tobacco mosaic virus (TMV), whereas the nondepolymerized carrageenan iota failed to induce protection against a viral infection (unpublished results). Thus, in our hands, depolymerization of carrageenans is strictly required to obtain an efficient stimulation of growth and protection against pathogens in tobacco plants.

Regarding oligo-carrageenans, it was initially shown that oligo-carrageenans kappa, lambda, and iota, with DPs of $1-3,3-9$, and 2-6, respectively, stimulate embryogenesis of broccoli microspores, especially oligo-carrageenan lambda (Lemonnier-Le Penhuizic and others 2001). In addition, oligo-carrageenan kappa, obtained by depolymerization with $\gamma$-radiation, enhanced the growth of roots and shoots in rice plants (Abad and others 2004). We prepared oligo-carrageenans kappa, lambda, and iota with a DP of around 20 by acid hydrolysis of pure commercial carrageenans (Moenne 2009). These oligo-carrageenans, at a concentration of $0.5-5 \mathrm{mg} \mathrm{ml}^{-1}$, induced an increase in plant height and leaf biomass in tobacco plants (var. Xanthi), especially oligocarrageenan kappa (Moenne 2009). It was further determined that oligo-carrageenans kappa, lambda, and iota, at a concentration of $1 \mathrm{mg} \mathrm{ml}^{-1}$, induced an increase in the height and leaf biomass in commercial tobacco plants (var. Burley), especially with oligo-carrageenans iota and kappa. These oligo-carrageenans increase net photosynthesis, rubisco activity, glutamate dehydrogenase activity involved in nitrogen assimilation, basal metabolism, and cell division in tobacco plants (Castro and others 2012). Considering that oligo-carrageenans increase rubisco activity, $\mathrm{CO}_{2}$ fixation might be enhanced, which could be very useful for cleaning the air polluted with $\mathrm{CO}_{2}$ released by industrial activity (Moenne and others 2010). Interestingly, tobacco plants (var. Burley) treated with oligo-carrageenans showed an increase in the level of transcripts encoding cyclins $\mathrm{A}$ and $\mathrm{D}$ and cyclin-dependent protein kinases (CDK) A and B, which indicates that cell cycle activity is increased and, thus, cell division (Castro and others 2012). In this sense, it is important to mention that cell size in control and treated tobacco plants was similar, indicating that the increase in height and foliar biomass is due to an increase in the number of cells, meaning that cell division is increased. On the other hand, oligo-carrageenans kappa, lambda, and iota enhanced protection against viral, fungal, and bacterial infection in tobacco plants (var. Xanthi), which was determined, at least in part, by the accumulation of PPCs with antimicrobial activities such as salicylic acid, dihydrobenzoic acid, vanillic acid, gallic acid, caffeic acid, ferulic acid, chlorogenic acid, scopoletin, esculetin, kaempferol, and quercetin (Vera and others 2012). Furthermore, oligo-carrageenans induced the partial suppression of viral, fungal, and bacterial infections which is also probably due to the accumulation of PPCs with antimicrobial activities (Vera and others 2012). Thus, oligocarrageenans stimulate growth and protection against pathogens in tobacco plants, suggesting that they are crosstalking signaling pathways.

\section{Oligo-carrageenans Stimulate Growth in Trees}

It was further determined that oligo-carrageenans kappa, lambda, and iota stimulate the growth of 3-year-old Eucalyptus globulus trees by increasing the height and trunk diameter. The stimulation of eucalyptus growth was due, at least in part, to an increased photosynthesis, 
nitrogen assimilation, and basal metabolism. It is important to mention that the activities of ammonium-fixating enzymes glutamine synthase $(\mathrm{GlnS})$ and glutamate dehydrogenase $(\mathrm{GDH})$ were increased in eucalyptus treated with oligo-carrageenans, mainly the activity of the key regulatory enzyme GlnS. In addition, the activity of the first enzyme of the Krebs cycle, pyruvate dehydrogenase (PDH), was also increased, suggesting that the amount of 2-oxoglutarate required for ammonium fixation by GDH may also be increased. On the other hand, oligo-carrageenans kappa, lambda, and iota enhanced the content of holocellulose (cellulose + hemicellulose) and $\alpha$-cellulose (long chains of cellulose) in the wood of treated eucalyptus. The increase in holocellulose indicates that the lignin content is decreased, which is also a suitable trait for the industrial production of cellulose. In addition, oligo-carrageenans induced an increase in height of $E$. nitens trees, suggesting that the effects observed in E. globulus may also occur in other eucalyptus species (unpublished results). On the other hand, leaves of treated eucalyptus trees showed an enhanced content of essential oils (terpenes) having antimicrobial activities. Eucalyptus essential oil is composed of mainly the monoterpenes eucalyptol, $\alpha$-pinene, and D-limonene and eucalyptol has recognized antiviral, antifungal, and antibacterial properties. Furthermore, oligocarrageenans increased the content of some PPCs in eucalyptus trees that have antimicrobial properties, including genistein, rutin, ellagic acid, morin, and quercetin. The increase in essential oil and in some PPCs with antimicrobial properties suggests that treated eucalyptus trees may exhibit an enhanced protection against pathogens. Thus, oligo-carrageenans stimulate growth and defense against pathogens in eucalyptus trees, suggesting that both signaling pathways are interconnected.

\section{Molecular Mechanisms Potentially Involved in Activation of Plant Growth and Defense}

Regarding molecular mechanisms involved in perception and signaling of oligo-alginates and oligo-carrageenans in animal cells, it has been demonstrated that the PM fraction (or Poly-Ma) activates cytokine production in human monocytes and mouse macrophages through the binding of this oligo-alginate to toll-like receptors (TLR) 2 and 4 located in the plasma membrane, in a CD14-dependent manner (Flo and others 2002). In addition, the PM and PG unsaturated fractions, obtained by digestion of alginates with a bacterial alginate lyase, induced secretion of tumor necrosis factor (TNF)- $\alpha$ and interleukins from mouse macrophages, especially the PM and PG fractions with a DP = 3-9, and that both oligo-alginates bind to TLR2 and TLR4 receptors (Iwamoto and others 2005, 2007). On the other hand, it was shown that carrageenan lambda activates interleukin secretion from human colonic epithelial cells and mouse macrophages by binding to TLR4 located in the plasma membrane, which activates signaling pathways and leads to activation of NFKB transcription factor (Borthakur and others 2007; Bhattacharyya and others 2008). In addition, it was determined that carrageenan lambda, digested with an $\alpha-1 \rightarrow(3,6)$-galactosidase, showed a reduced effect on interleukin secretion from human colonic epithelial cells. In contrast, lambda carrageenan, hydrolyzed with $\alpha-1 \rightarrow 6, \beta-1 \rightarrow 4$, or $\beta-1 \rightarrow(3,6)$-galactosidases, properly activates interleukin secretion. These results suggest that the unusual $\alpha$-D-Gal-( $1 \rightarrow 3)$-D-Gal epitope may interact with TLR4 (Bhattacharyya and others 2010).

With respect to interaction of oligo-alginates and oligocarrageenans with plant cells, the potential plasma membrane receptors and the associated signaling pathways have not yet been identified. It has been determined that plant cell genomes encode several hundred plasma membrane receptors with protein kinase activity and that some of them are structurally related to animal TLRs, in particular in Arabidopsis and rice genomes (Nürnberger and others 2004; Shiu and others 2004; Lethi-Shiu and others 2009). Thus, it is possible that oligo-alginates and oligo-carrageenans may interact with a specific receptor structurally related to TLR4 and/or TLR2 or with another yet unidentified receptor with protein kinase activity. Concerning the amazing double effect of oligo-alginates and oligo-carrageenans of stimulating plant growth and providing defense against pathogens, it has been demonstrated that brassinosteroids, which are polyhydroxylated plant steroidal hormones involved in stem elongation, leaf development, pollen tube growth, and photomorphogenesis, bind to a specific receptor located in the plasma membrane which, in turn, interacts with a coreceptor named BRI1-associated receptor kinase $(\mathrm{BAK}) 1$ that activates signal transduction (Nam and Li 2002). On the other hand, bacterial microbialassociated molecular patterns (MAMPs) such as flagellin, elongation factor (EF)-Tu, and peptidoglycan bind to specific receptors that also interact with BAK1, which activates signal transduction (Chinchilla and others 2007; Postel and others 2010). Thus, activation of brassinosteroid-dependent and MAMPs-dependent signaling pathways involve a common coreceptor (BAK1) which may determine the interdependence of plant growth and defense response activation (Kemmerling and others 2011). In fact, equilibrated stimuli of brassinosteroids and MAMPs are required to obtain an efficient activation of these pathways since an excess of brassinosteroids inhibits defense responses (Belkhadir and others 2012). It is possible that specific receptors for oligo-alginates and oligo-carrageenans may exist in plant plasma membranes and require a coreceptor involved in signal transduction of plant growth 
stimuli, thus explaining the ability of seaweed oligosaccharides to trigger simultaneous activation of plant growth and defense against pathogens.

\section{Conclusions}

Seaweed polysaccharides, and mainly their derived-oligosaccharides, stimulate growth of terrestrial plants and trees by enhancing carbon and nitrogen assimilation, basal metabolism, and cell division as well as the level of essential oil and/or PPCs with antimicrobial properties, which may determine an enhanced protection against pathogens. In addition, the dual beneficial effect observed for oligo-alginates and oligo-carrageenans on plant growth and defense may involve the binding of these oligosaccharides to specific plasma membrane receptors that use a coreceptor involved in signal transduction of plant growth stimuli, leading to the simultaneous activation of plant growth and defense against pathogens.

Acknowledgments This work was financed by VRID-USACH and by Sirius Natura S.A. (www.siriusnatura.cl).

Open Access This article is distributed under the terms of the Creative Commons Attribution License which permits any use, distribution, and reproduction in any medium, provided the original author(s) and the source are credited.

\section{References}

Abad LV, Nasimova IR, Relleve LS, Aranilla CT, De la Rosa AM, Shibayama M (2004) Dynamic light scattering studies of irradiated kappa carrageenan. Int J Biol Macromol 34:81-88

Albersheim P, Darvill A, Augur C, Cheong JJ, Eberhard S, Hahn MG, Marfá V, Mohnen D, O'Neill MA, Spiro MD, York WS (1992) Oligosaccharins: oligosaccharide regulatory molecules. Acc Chem Res 25:77-83

Augur C, Yu L, Sakai K, Ogawa T, Sinay P, Darvill AG, Albersheim P (1992) Further studies of the ability of xyloglucan oligosaccharides to inhibit auxin-stimulated growth. Plant Physiol 99:180-185

Belkhadir Y, Jallais Y, Epple P, Balsemao-Pires E, Dangl JL, Chory J (2012) Brassinosteroids modulate the efficiency of plant immune responses to microbe-associated molecular patterns. Proc Natl Acad Sci U S A 109:297-302

Bhattacharyya S, Gill R, Chen ML, Zhang F, Linhardt RJ, Dudeja PK, Tobacman JK (2008) Toll-like receptor 4 mediates induction of Bcl10-NFkB-interleukin 8 inflammatory pathway by carrageenan in human intestinal epithelial cells. J Biol Chem 283:10550-10558

Bhattacharyya S, Liu H, Zhang Z, Jam M, Dudeja PK, Michel G, Linhardt RJ, Tobacman JK (2010) Carrageenan-induced innate immune response is modified by enzymes that hydrolyze distinct galactosidic bonds. J Nutr Biochem 21:906-913

Bi F, Iqbal S, Arman M, Ali A, Hassan M (2011) Carrageenan as an elicitor of induced secondary metabolites and its effect on various growth characters of chickpea and maize plants. J Saudi Chem Soc 15:269-273

Borthakur A, Bhattacharyya S, Dudeja PK, Tobacman JK (2007) Carrageenan induces interleukin-8 production through distinct BCL10 pathway in normal human colonic epithelial cells. Am J Physiol Gastrointest Liver Physiol 292:829-838

Castro J, Vera J, González A, Moenne A (2012) Oligo-carrageenans stimulate growth by enhancing photosynthesis, basal metabolism, and cell cycle in tobacco plants (var. Burley). J Plant Growth Regul 31:173-185

Chinchilla D, Zipfel C, Robatzek S, Kemmerling B, Nürnberger T, Jones JD, Felix G, Boller T (2007) A flagellin-induced complex of the receptor FLS2 and BAK1 initiates plant defence. Nature 448:497-500

Eberhard S, Doubrava N, Marfá V, Mohnen D, Southwick A, Darvill A, Albersheim P (1989) Pectic cell wall fragments regulate tobacco thin-cell-layer explant morphogenesis. Plant Cell 1:747755

Flo T, Ryan L, Latz E, Takeuchi O, Moncks BG, Lien E, Halaas O, Akira S, Skjak-Braek G, Golenbock DT, Espevik T (2002) Involvement of Toll-like Receptor (TLR) 2 and TLR4 in cell activation by mannuronic acid polymers. J Biol Chem 277: 35489-35495

Hien NQ, Nagasawa N, Tham LX, Yoshii F, Dang VH, Mitomo H, Makuuchi K, Kume T (2000) Growth promotion of plants with depolymerized alginates by irradiation. Radiat Phys Chem 59:97-101

Hu XK, Jiang XL, Hwang HM, Liu SL, Guan HS (2004) Promotive effects of alginate-derived oligosaccharide on maize seed germination. J Appl Phycol 16:73-76

Iwamoto M, Kurachi M, Nakashima T, Kim D, Yamaguchi K, Oda T, Iwamoto Y, Muramatsu T (2005) Structure-activity relationship of alginate oligosaccharides in the induction of cytokine production from RAW264.7 cells. FEBS Lett 579:4423-4429

Iwamoto Y, Kurachi M, Yamaguchi K, Oda T (2007) Induction of multiple cytokines from RAW264.7 cells by alginate oligosaccharides. Biosci Biotechnol Biochem 71:238-241

Iwasaki KI, Matsubara Y (2000) Purification of alginate oligosaccharides with root growth-promoting activity toward lettuce. Biosci Biotechnol Biochem 64:1067-1070

Jin DF, West CA (1984) Characteristics of galacturonic acid oligomers as elicitors of casbene synthetase activity in castor bean seedlings. Plant Physiol 74:989-992

John M, Rohrig H, Schmidt J, Walden R, Schell J (1997) Cell signalling by oligosaccharides. Trends Plant Sci 2:111-115

Kemmerling B, Halter T, Mazzota S, Mosher S, Nürnberger T (2011) A genome-wide survey for Arabidopsis leucine-rich repeat receptor kinases implicated in plant immunity. Front Plant Sci 2:1-6

Khan ZH, Khan MM, Aftab T, Indrees M, Naeem M (2011) Influence of alginate oligosaccharides on growth, yield and alkaloid production of opium poppy (Papaver somniferum L.). Front Agric China 5:122-127

Laporte D, Vera J, Chandía NP, Zúniga E, Matsuhiro B, Moenne A (2007) Structurally unrelated oligosaccharides obtained from marine macroalgae differentially stimulate growth and defense against TMV in tobacco plants. J Appl Phycol 19:79-88

Lehti-Shiu MD, Zou C, Hanada K, Shiu SH (2009) Evolutionary history and stress regulation of plant receptor-like kinases/pelle genes. Plant Physiol 150:12-26

Lemonnier-Le Penhuizic C, Chatelet C, Kloareg B, Potin P (2001) Carrageenan oligosaccharides enhance stress-induced microspore embryogenesis in Brassica oleracea var. italica. Plant Sci 160:1211-1220

McDougall GJ, Fry SC (1990) Xyloglucan oligosaccharides promote growth and activate cellulase: evidence for a role of cellulase in cell expansion. Plant Physiol 93:1042-1048 
Mercier L, Lafitte C, Borderies G, Briand X, Esquerré-Tugayé MT, Fournier J (2001) The algal polysaccharide carrageenans can act as an elicitor of plant defense. New Phytol 149:43-51

Moenne A (2009) Composition and method to stimulate growth and defense against pathogens in plants. U.S. Patent Office Application No. 12,666,700

Moenne A, Castro J, Vera J (2010) Method to stimulate carbon fixation in plants with an aqueous solution of oligo-carrageenans selected from kappa1, kappa2, lambda and iota. U.S. Patent Office Application No. 12,911,790

Nam KH, Li J (2002) BRI1/BAK1, a receptor kinases pair mediating brassinosteroid signaling. Cell 110:203-212

Nothnagel EA, McNeil M, Albersheim P, Dell A (1983) Hostpathogen interactions: a galacturonic acid oligosaccharide from plant cell walls elicits phytoalexins. Plant Physiol 71:916-926

Nürnberger T, Brunner F, Kemmerling B, Piater L (2004) Innate immunity in plants and animals. Striking similarities and obvious differences. Immunol Rev 198:249-266

Postel S, Küfner I, Beuter C, Mazzota S, Schwedt A, Borlotti A, Halter T, Kemmerling B, Nürnberger T (2010) The multifunctional leucine-rich repeat receptor kinase BAK1 is implicated in Arabidospsis development and immunity. Eur J Cell Biol 89:169-174

Röhrig H, Schmidt J, Walden R, Czaja I, Wieneke U, Schell J, John M (1995) Growth of tobacco protoplasts stimulated by synthetic lipo-chitooligosaccharides. Science 269:841-843

Röhrig H, Schmidt J, Walden R, Czaja I, Lubenow H, Wieneke U, Schell J, John M (1996) Convergent pathways for lipochitooligosaccharide and auxin signaling in tobacco cells. Proc Natl Acad Sci U S A 93:13389-13392

Sarfaraz A, Naeem M, Nasir S, Idrees M, Aftab T, Hashmi N, Masroor AK, Khan MM, Varshney L (2011) An evaluation of the effects of irradiated sodium alginate on the growth, physiological activities and essential oil production of fennel (Foeniculum vulgare Mill.). J Med Plant Res 5:15-21

Sharp JK, Valent B, Albersheim P (1984) Purification and partial characterization of a beta-glucan fragment that elicits phytoalexin accumulation in soybean. J Biol Chem 259: $11312-11320$

Shiu SH, Karlowski WM, Pan R, Tzeng Y, Mayer KF, Li WH (2004) Comparative analysis of receptor-like kinase family in Arabidopsis and rice. Plant Cell 16:1220-1234

Van Tran Thanh K, Toubart P, Cousson A, Darvill AG, Gollin DJ, Chelf P, Albersheim P (1985) Manipulation of the morphogenetic pathways of tobacco explants by oligosaccharins. Nature 314:615-617

Vera J, Castro J, González A, Moenne A (2011) Seaweed polysaccharides and derived oligosaccharides stimulate defense responses and protection against pathogens in plants. Mar Drugs 9:2514-2525

Vera J, Castro J, González A, Moenne A (2012) Oligo-carrageenans induced a long-term and broad-range protection against pathogens and the reversion of infections in tobacco plants (var. Xanthi). Physiol Mol Plant Pathol 79:31-39

Xu X, Iwamoto Y, Kitamura Y, Oda T, Muramatsu T (2003) Root growth-promoting activity of unsaturated oligomeric uronates from alginate on carrot and rice plants. Biosci Biotechnol Biochem 67:2022-2025

Yamasaki Y, Yokose T, Nishikawa T, Kim D, Jiang Z, Yamaguchi K, Oda T (2012) Effects of alginate oligosaccharide mixtures on the growth and fatty acid composition of the green alga Chlamydomonas reinhardtii. J Biosci Bioeng 113:112-116

Yokose T, Nishikawa T, Yamamoto Y, Yamazaki Y, Yamaguchi K, Oda T (2009) Growth-promoting effect of alginate oligosaccharides on a unicellular marine microalga, Nannochloropsis oculata. Biosci Biotechnol Biochem 73:450-453

Yokose T, Yamasaki Y, Nishikawa T, Jiang Z, Wang Y, Yamaguchi $\mathrm{K}$, Oda T (2010) Effects of alginate oligosaccharides on the growth of various mammalian cell lines, unicellular phytoplankters and marine bacteria. Jpn J Food Chem Saf 17:27-35

York WS, Darvill AG, Albersheim P (1984) Inhibition of 2,4dichlorophenoxyacetic acid-stimulated elongation of pea stem segments by a xyloglucan oligosaccharide. Plant Physiol 75:295-297 